This document is the Accepted Manuscript version of a Published Work that appeared in final form in Analytical Chemistry, copyright (c) American Chemical Society after peer review and technical editing by the publisher. To access the final edited and published work see:

https://dx.doi.org/10.1021/acs. analchem.9b00340. 


\title{
In situ plant virus nucleic acid isothermal amplification detection on gold nanoparticle-modified electrodes
}

Mohga Khater ${ }^{1,2}$, Alfredo de la Escosura-Muñiz ${ }^{1}$, Laura Altet ${ }^{3}$,

\author{
Arben Merkoçi $i^{1,4 *}$
}

${ }^{1}$ Catalan Institute of Nanoscience and Nanotechnology (ICN2), CSIC and Barcelona Institute of Science and Technology, Campus UAB, 08193 Barcelona, Spain.

${ }^{2}$ On leave from Agricultural Research Center (ARC), Ministry of Agriculture and land reclamation, Giza, Egypt

${ }^{3}$ Vetgenomics, Edifici Eureka, Parc de Recerca UAB, 08193 Bellaterra (Barcelona), Spain

${ }^{4}$ ICREA-Institucio Catalana de Recerca i Estudis Avançats, Pg. Lluís Companys 23, 08010 Barcelona, Spain.

Phone number: +34937374604 ; Fax number: +34935868020

*E-mail: arben.merkoci@icn2.cat 


\section{ABSTRACT}

Solid-phase isothermal recombinase polymerase amplification (RPA) offers many benefits over the standard RPA in homogeneous phase in terms of sensitivity, portability and versatility. However, RPA devices reported to date are limited by the need for heating sources to reach sensitive detection. With the aim of overcoming such limitation, we propose here a label-free highly integrated in situ RPA amplification/detection approach at room temperature that takes advantage of the high sensitivity offered by gold nanoparticle (AuNP)-modified sensing substrates and electrochemical impedance spectroscopic (EIS) detection. Plant disease (Citrus tristeza virus (CTV)) diagnostics was selected as relevant target for the demonstration of the proof-of-concept. RPA assay for the amplification of the P20 gene (387-bp) characteristic of CTV was first designed/optimized and tested by standard gel electrophoresis analysis. The optimized RPA conditions were then transferred to the AuNP-modified electrode surface, previously modified with a thiolated forward primer. The in situ amplified CTV target was investigated by EIS in $\mathrm{Fe}\left(\mathrm{CN}_{6}\right)^{4-} / \mathrm{Fe}\left(\mathrm{CN}_{6}\right)^{3-}$ red-ox system, being able to quantitatively detect $1000 \mathrm{fg} \mu \mathrm{L}^{-1}$ of nucleic acid. High selectivity against non-specific gene sequences characteristic of potential interfering species such as Citrus psorosis virus (CPsV) and Citrus caxicia viroid (CCaV), was demonstrated. Good reproducibility (RSD of $8 \%$ ) and long-term stability (up to 3 weeks) of the system were also obtained. Overall, with regard to sensitivity, cost and portability, our approach exhibits better performance than RPA in homogeneous phase, also without the need of heating sources required in other solid-phase approaches.

\section{KEYWORDS}

Electrochemical impedance spectroscopy, DNA, Gold-nanoparticles, Virus, Plant pathogen, citrus tristeza virus, isothermal amplification 


\section{INTRODUCTION}

Recombinase polymerase amplification (RPA) has received much attention in recent years due to its versatility and isothermal performance, which may offer effective replacement to Polymerase chain reaction (PCR) in molecular detection. ${ }^{1-4}$ Unlike PCR, RPA technology is based on three main components (recombinase, single-stranded DNA-binding protein and polymerase) which allow amplification at constant temperature (ranging from $37^{\circ} \mathrm{C}-40^{\circ} \mathrm{C}$ ) and as a result the need for thermal cycling is omitted. ${ }^{5,6}$ The required temperature for RPA is lower than for other emerged isothermal amplification methods such as nucleic acid sequence-based amplification (NASBA), loop-mediated isothermal amplification (LAMP), rolling circle amplification (RCA) and helicase dependent amplification (HDA) ${ }^{7-11}$ In spite of the great advantages of RPA, DNA purification and detection after amplification involving hazardous, time-consuming and expensive equipment is still required for getting qualitative information. Alternative methodologies taking advantage of the use of labeled primers for detecting RPA amplified products in lateral flow ${ }^{12-14}$, and electrochemical approaches have been proposed for such purpose. ${ }^{15,16}$ Some efforts have been also devoted to RPA integration into microfluidic devices with fluorescence detection. ${ }^{17}$ However, these methods lack of integration of RPA amplification and detection in the same device, which would be strongly needed for in-field diagnostic applications.

Such highly integrated devices have been recently achieved with the so-called solid-phase RPA amplification, in which one of the primers is directly immobilized on the sensing surface. Label-free optical approaches ${ }^{18,19}$, and enzymatic label-based electrochemical ones with high degree of integration have been reported. ${ }^{20}$ However, heat sources are needed for getting detectable signals, which represents an important practical limitation.

In this context, we propose a label-free highly integrated in situ RPA amplification/detection approach at room temperature, taking advantage of the high sensitivity achieved combining 
the use of gold nanoparticle (AuNP)-modified sensing substrates and electrochemical impedance spectroscopic (EIS) detection. Plant disease (Citrus tristeza virus (CTV)) is selected as relevant target for the demonstration of the proof-of-concept. Recent studies estimating that plant diseases may cause global economic losses exceeding billions of dollars annually put in value the relevance of such diseases. ${ }^{21}$ Early detection of pathogens in presymptomatic plants is of key importance for avoiding the development and spread of the disease. Plant pathogen determination is currently performed through antibody-based enzyme-linked immunosorbent assays (ELISA) and lateral flow immunoassays (LFIA) ${ }^{22-28}$ , and nucleic acid-based analysis ${ }^{29-31}$, as alternative to the traditional diagnostic methods including symptoms observation, regular in-field inspections, and laboratory analysis by experienced plant pathologists.${ }^{32}$ Over the last decade, it has been noticed that antibody and DNA based biosensing applications in the field of plant disease diagnostics have been increasing . 33-36 However, highly integrated approaches for in-field detection in presymptomatic plants, like the one we are proposing in this work, are still missing. 


\section{EXPERIMENTAL SECTION}

\subsection{Chemicals and equipment}

Gold (III) chloride hydrate $\left(\mathrm{HAuCl}_{4}, 99.9 \%\right)$, potassium hexacyanoferrate (III), potassium hexacyanoferrate (II), tris (2-carboxyethyl) phosphine (TCEP), $\mathrm{NaCl}, \mathrm{MgCl}_{2}, \mathrm{CaCl}_{2}$, 6Mercaptohexanol $(\mathrm{MCH})$ and phosphate buffered saline were obtained from Sigma Aldrich (Spain). The target and control sequences together with six primers were synthesized by Integrated DNA Technologies (Coralville, USA) (Table S1, in the supplementary information). TwistAmp Basic Kit containing all enzymes and reagents necessary for the amplification of DNA (TwistDx Ltd, Cambridge, UK). For purification of post-amplification DNA products, DNA clean and concentrator kit was purchased from Ecogen (Spain). Thiolated primer was pre-treated as detailed at the supplementary information. All buffer solutions were prepared with ultrapure water of Milli-Q water purification system (with resistivity of $18.2 \mathrm{M} \Omega \mathrm{cm})$. The supporting electrolyte was $0.5 \mathrm{mM}$ solution of $\mathrm{K}_{3}\left[\mathrm{Fe}(\mathrm{CN})_{6}\right] / \mathrm{K}_{4}\left[\mathrm{Fe}(\mathrm{CN})_{6}\right]$ in $0.1 \mathrm{M} \mathrm{KCl}$. Thiolated primer was diluted in $34 \mathrm{mM}$ Tris- $\mathrm{HCl}$, $\mathrm{pH}$ 7.4 buffer. The washing solutions were $0.01 \mathrm{M}$ phosphate buffered saline (PBS; pH 7.4), PBST (PBS and 0.05\% (v/v) Tween 20, pH 7.4) and 2× SCC buffer (300 mM sodium chloride $30 \mathrm{mM}$ sodium citrate), with $\mathrm{pH}$ adjusted to 7.2. Stock solutions of the oligonucleotides were prepared in TE (0.01 M Tris-HCl; pH 8.2 and $0.001 \mathrm{M}$ EDTA) buffer solution and kept frozen at $-20^{\circ} \mathrm{C}$. Ultrapure agarose and 50X TAE buffer (Tris-acetateEDTA) were purchased from Invitrogen for electrophoresis of amplified nucleic acid. The agarose gel was stained by the green fluorescent Midori DNA stain. Electrophoresis was carried out using Mupid®-one and followed by gel-documentation under UV light at $300 \mathrm{~nm}$. Nanodrop 1000 was used to quantify of DNA concentrations after RPA amplification with thiolated forward primer. Block heater was used for the incubation of RPA reactions. All 
electrochemical measurements were recorded using Autolab potentiosat PGS00 supported by FRA for impedance spectra analysis. Home-made screen-printed carbon electrodes (SPCEs) preparation is detailed at the supplementary information.

\subsection{Methods}

\subsubsection{RPA assay of CTV related nucleic acid}

The sequence of p20 gene (549nt) responsible for systemic infection was first selected in CTV genome. Such sequence is specific to CTV and does not relate to other closteridea viruses, major component of CTV and highly produced in infected trees. Three forward and two reverse primers were designed (between 25 and $35 \mathrm{bp}$ ) to amplify the p20 of 378-bp of CTV genomic nucleic acid, following the RPA manufacture's manual. Then the primer combinations were screened by gel electrophoresis in order to select the optimal primer pair which has great sensitivity and specificity for CTV.

For the RPA assays ( $50 \mu \mathrm{L}$ reaction volume), a master mix composed of $2.4 \mu \mathrm{L}$ of primers $(10 \mu \mathrm{M}), 29.5 \mu \mathrm{L}$ of rehydration buffer and $13.8 \mu \mathrm{L}$ of CTV-p20 gene and DNase-free water was first prepared. After dividing aliquots of the master mix into reaction tubes and mixing with TwistAmp basic Freeze-dried enzyme pellets, the RPA reactions were started immediately by adding magnesium acetate $(280 \mathrm{mM})$. The reaction tubes were incubated at $37^{\circ} \mathrm{C}$ for $30 \mathrm{~min}$. RPA reactions were performed without the target gene as no template control (NTC). Following post-amplification purification, amplicons were analysed in 2\% agarose gel.

\subsubsection{In situ isothermal RPA on gold nanoparticle modified electrodes}

SPCEs modification with AuNPs and thiolated nucleic acid immobilization were performed following a previously optimized procedure (Khater et al., 2017). Briefly, the electrodes were 
pre-treated by applying oxidative potentials of $+1.6 \mathrm{~V}$ for $120 \mathrm{~s}$ and of $+1.8 \mathrm{~V}$ for $60 \mathrm{~s}$ in acetate buffer, followed by rinsing with PBS and Milli-Q water (3X) and dried using nitrogen. Carbon working electrodes were then immersed into a gold solution $(0.01 \% \mathrm{HAuCl} 4$, / $0.1 \mathrm{M}$ $\mathrm{NaCl}$ in the presence of $1.5 \mathrm{wt} \% \mathrm{HCl}$ ) and a constant negative potential of $-0.4 \mathrm{~V}$ for $200 \mathrm{~s}$ was applied for achieving a homogenous formation of well distributed spherical AuNPs of 50 nm. The thiolated forward primer $\left(\mathrm{SH}-\left(\mathrm{AT}_{7}\right)-\mathrm{F} 1\right)$ was pre-reduced using TCEP as detailed at the supplementary information. AuNP-modified SPCEs were then incubated with $15 \mu \mathrm{L}$ of $0.1 \mu \mathrm{M}$ SH-( $\left.\mathrm{AT}_{7}\right)-\mathrm{F} 1$ prepared with $1 \mathrm{mM} \mathrm{MCH}$ solution at ratio (1:0.1) for $2 \mathrm{~h}$ at room temperature. After that, the electrodes were thoroughly rinsed using PBS and dried with nitrogen gas.

RPA solutions were then prepared for the surface amplification and detection of the target sequence of $\left(\mathrm{P}_{20}\right.$ gene) on the AuNP-modified SPCEs. For master mix of RPA reaction preparation, $29.5 \mu \mathrm{L}$ of rehydration buffer, $2.4 \mu \mathrm{L}$ of reverse primer $(10 \mu \mathrm{M})$ and $13.2 \mu \mathrm{L}$ of DNase-free water were mixed and added to the freeze-dried enzyme pellet. Then, this mixture was mixed well with $2.5 \mu \mathrm{L}$ of magnesium acetate at concentration of $280 \mathrm{mM}$. After that, the $50 \mu \mathrm{L}$ reaction volume was divided into $10 \mu \mathrm{L}$ aliquots and added to AuNP-modified SPCEs. Finally, $5 \mu \mathrm{L}$ of the P20 gene from the target plant virus genome that ranges in concentrations from $1 \mathrm{pg} \mu \mathrm{L}^{-1}$ to $1 \mathrm{ng} \mu \mathrm{L}^{-1}$ was added to the previously prepared $10 \mu \mathrm{L}$ RPA solution. The solid phase isothermal amplification assays were performed at room temperature $\left(25 \pm 3^{\circ} \mathrm{C}\right)$ for 60 min. Additionally, the AuNP-modified SPCEs with RPA solutions containing water or other unrelated DNAs as negative controls were evaluated. A scheme of the developed nucleic acid amplification/detection system is shown at Figure 1. 


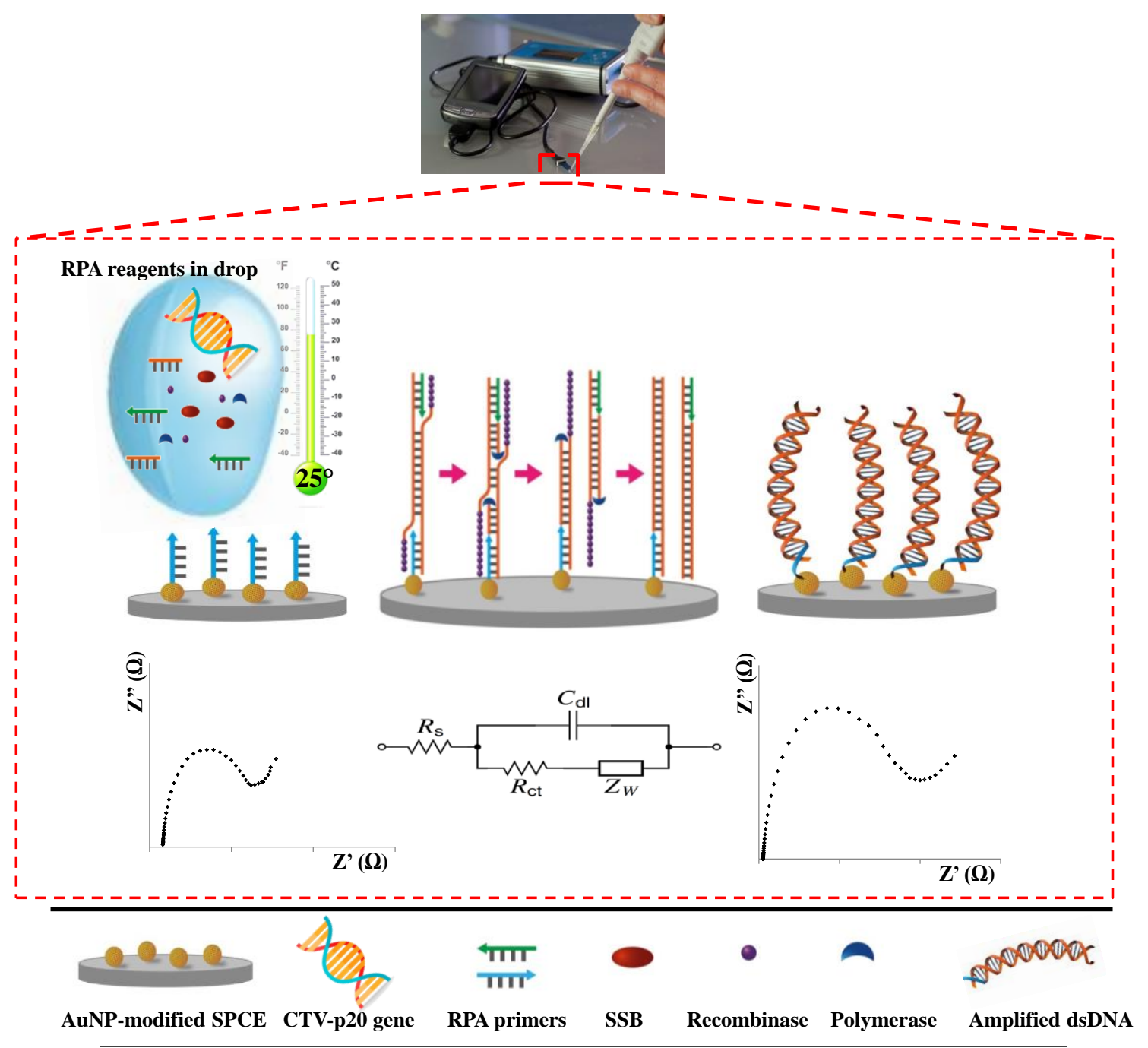

Figure 1. The stepwise of the developed label-free in situ isothermal RPA amplification/detection biosensor on primer-modified SPCE-AuNP electrodes employing impedance for the determination of CTV-related nucleic acid.

\subsubsection{Electrochemical measurements}

The in situ isothermal RPA was characterized by electrochemical impedance spectroscopy (EIS). Impedance measurements were performed in $0.5 \mathrm{mM} \mathrm{K}_{3}\left[\mathrm{Fe}(\mathrm{CN})_{6}\right] / \mathrm{K}_{4}\left[\mathrm{Fe}(\mathrm{CN})_{6}\right]$ in 0.1 $\mathrm{M} \mathrm{KCl}$ within frequency ranging from $10 \mathrm{KHz}$ to $0.005 \mathrm{~Hz}$ and alternating voltage amplitude of $5 \mathrm{mV}$. The Nyquist plots of impedance which represent the system dynamics were employed to detect the isothermal amplified DNA (278- bp) on the AuNP-modified SPCEs. 
The change in the semicircle diameter of the impedance represents the charge transfer resistance $\left(\mathrm{R}_{\mathrm{ct}}\right)$ of $\mathrm{Fe}\left[(\mathrm{CN})_{6}\right]^{4-/ 3-}$ at the modified electrode surface. The difference in charge transfer resistance before and after DNA amplification forming duplex DNA (dsDNA), $\left(\Delta \mathrm{R}_{\mathrm{ct}}\right)$ was obtained following the equation: $\Delta \mathrm{R}_{\mathrm{ct}}=\left(\mathrm{R}-\mathrm{R}_{0}\right) / \mathrm{R}_{0}$, where $\mathrm{R}$ and $\mathrm{R}_{0}$ are charge transfer resistance of amplified dsDNA and primer ssDNA, respectively. For accurate analytical analysis, the recorded $R_{c t}$ was fitted to the equivalent circuits (Randless circuit) using FRA. All EIS reported results were analyzed by calculating means and standard deviation to represent obtained data. All impedance experiments were conducted under ambient conditions.

\section{RESULTS AND DISCUSSION}

\subsection{Design of RPA for CTV detection assay}

After designing of RPA primers to specifically detect CTV, gel electrophoresis was carried out to screen the selected primer sets (Table S1, in the supplementary information). The best analytical band was produced by F1/R1 primer pair which was able to amplify the expected size amplicons of 278-bp, being then chosen for next experiments. The optimum conditions recommended by manufacturer, which included favorable temperature of $37^{\circ} \mathrm{C}$, total reaction volume $50 \mu \mathrm{L}$ and interval mixing upon $\mathrm{Mg}$ salt addition were applied to perform RPA reaction for $30 \mathrm{~min}$, resulting in amplified 278-bp CTV-p20 gene fragments in the

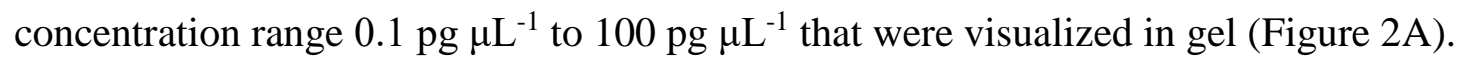

The ability of the RPA to work at room temperature $\left(25 \pm 3^{\circ} \mathrm{C}\right)$ was then evaluated. RPA experiments for CTV-p20 gene target concentration ranging from $0.1 \mathrm{pg} \mu \mathrm{L}^{-1}$ to $100 \mathrm{pg} \mu \mathrm{L}^{-1}$ were performed within $30 \mathrm{~min}$ amplification at such temperature. Products obtained gave detectable bands in the gel only for the higher concentrations assayed (100 pg $\mu \mathrm{L}^{-1}$ and $10 \mathrm{pg}$ $\mu \mathrm{L}^{-1}$ ) (Figure 2B), evidencing the DNA amplification under these conditions. 
RPA conditions were modified in order to be more suitable to perform in situ amplification on primer-modified SPCE-AuNP electrodes. With the aim of simulating the conditions that will be found on the electrode surface, small reaction volumes of $15 \mu \mathrm{L}$ were evaluated under amplification at $37^{\circ} \mathrm{C}$ and room temperature. The signals got from large reaction volumes of $50 \mu \mathrm{L}$ incubated at $37^{\circ} \mathrm{C}$ were detectable for CTV-p20 gene target concentration as low as 0.1 pg $\mu \mathrm{L}^{-1}$ while small reaction volumes of $15 \mu \mathrm{L}$ gave signals only detectable for target concentration as high as $10 \mathrm{pg} \mu \mathrm{L}^{-1}$ (Figure 2C). The $100 \mathrm{pg} \mu \mathrm{L}^{-1}$ CTV-p20 gene target concentration showed a detectable signal after amplification of the small volume at RT while no amplicons were generated from lower target concentrations (Figure 2D). The effect of $\mathrm{Mg}$ salt addition without mixing step was also evaluated, reaching the same sensitivity than with previous mixing (data not shown).

The good performance of the thiolated forward primer $\left(\mathrm{SH}-\left(\mathrm{AT}_{7}\right)-\mathrm{F} 1\right)$ was evaluated by Nanodrop nucleic acid quantification (see the supplementary information). 


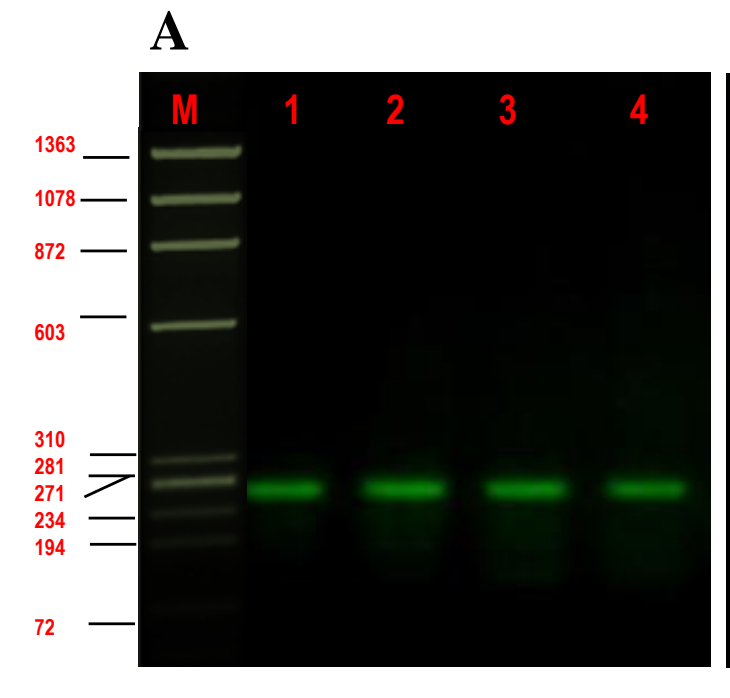

B
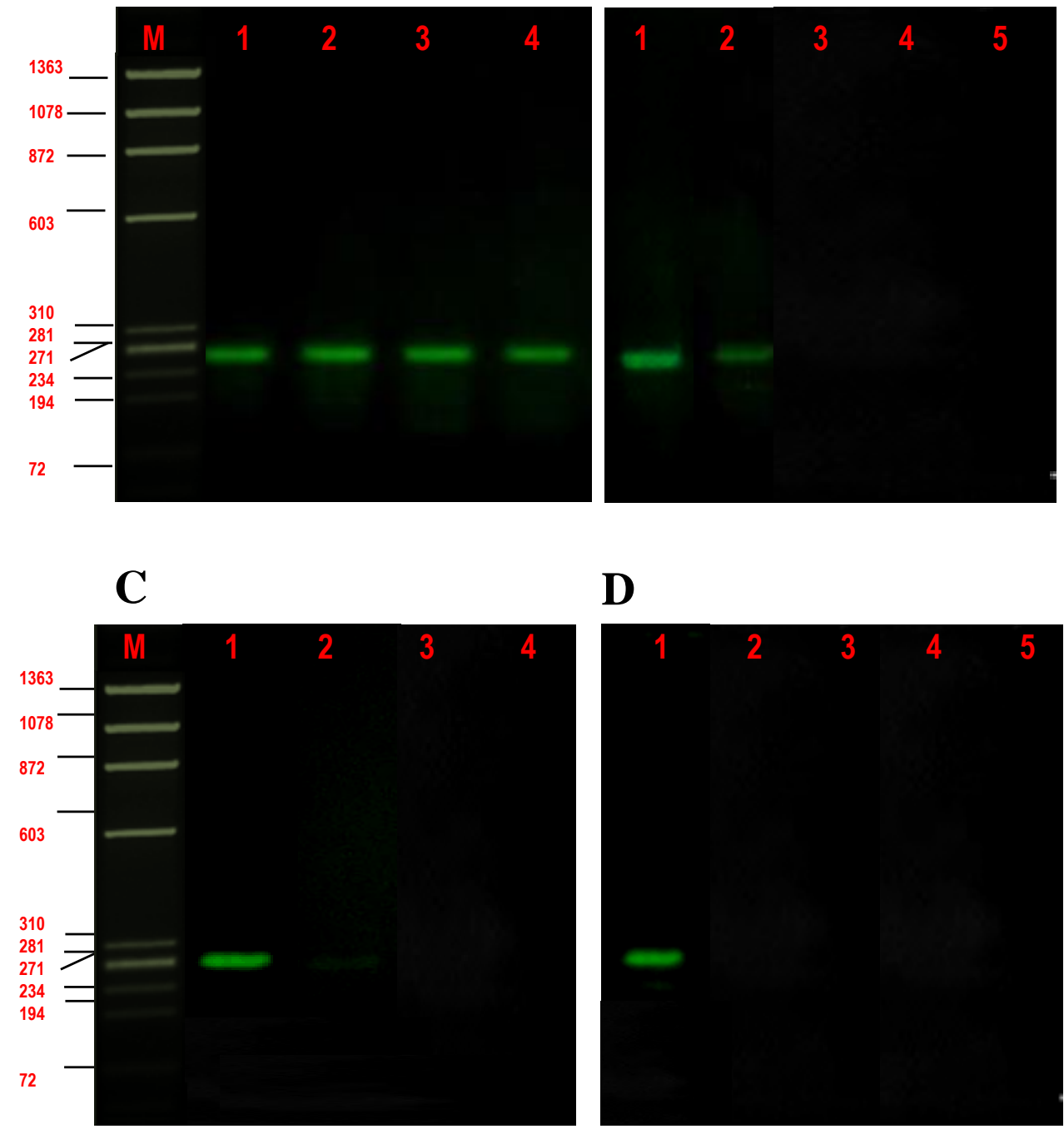

D

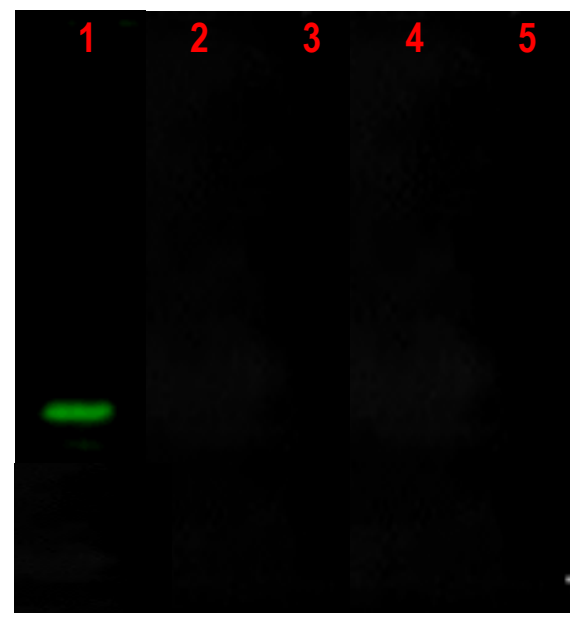

Figure 2. Gel electrophoresis analysis of RPA amplicons for CTV detection following A. Optimum isothermal RPA conditions: RPA amplification temperature: $37^{\circ} \mathrm{C}$; total reaction volume: $50 \mu \mathrm{L} \mathrm{B}$. Isothermal RPA reactions at room temperature with $50 \mu \mathrm{L}$ total reaction volume. Isothermal RPA of small reaction volume $(15 \mu \mathrm{L})$ incubated at different temperatures C. $37^{\circ} \mathrm{C}$ and $\mathbf{D}$. Room temperature. All isothermal RPA reaction times were $30 \mathrm{~min} . \mathrm{M}=\mathrm{Phi}-$ X 174/HaeIII Marker , $1=100 \mathrm{pg} \mu \mathrm{L}^{-1}, 2=10 \mathrm{pg} \mu \mathrm{L}^{-1}, 3=1 \mathrm{pg} \mu \mathrm{L}^{-1}, 4=0.1 \mathrm{pg} \mu \mathrm{L}^{-1}, 5=$ NTC. Bands size: 278-bp for CTV-p20 gene. 


\subsection{Electrochemical characterization and optimization of the in situ isothermal RPA on}

\section{the electrode surface}

The optimized RPA conditions were transferred to the SPCE-AuNP electrode surface. All the reagent solutions were added to the electrode, previously modified with the forward primer (SH-(AT $)-\mathrm{F} 1) . \quad \mathrm{CTV}-\mathrm{p} 20$ gene was lastly added to the RPA mixture on the electrode to start the reaction (Figure 1).

The Nyquist plots recorded for the electrodes showed a high increase in the electrode resistance upon the RPA performed with a CTV-p20 target concentration of $1 \mathrm{ng} \mu \mathrm{L}^{-1}$ (Figure 3A), demonstrating the attachment of amplified DNA to the electrode.

However, when testing RPA solutions with negative control, unspecific EIS response was observed (data not shown). In order to prevent the interference from RPA chemical reagents and to reduce unspecific adsorption of enzymes, the three most commonly used washing buffers in chips and microfluidic domain for nucleic acid amplification methods were evaluated. After amplification, electrodes were carefully washed with three different washing buffers PBS 10mM, 2x SSC and PBST containing 0.05\% (v/v) Tween 20. As a result of using PBST washing buffer, the unspecific EIS signal was highly decreased after amplifying with negative control showing the effective removal of the rest of RPA components that may remain on the electrode after amplification (Figure 3B). The supplement of Tween detergent in the washing buffer (PBST) resulted in greatly reduced non-specific binding of RPA reagents on electrode surfaces, suggesting their effective release. Moreover, it is important to note that the high viscosity of RPA solutions makes the post-amplification washing step essential for the EIS signal enhancement. 

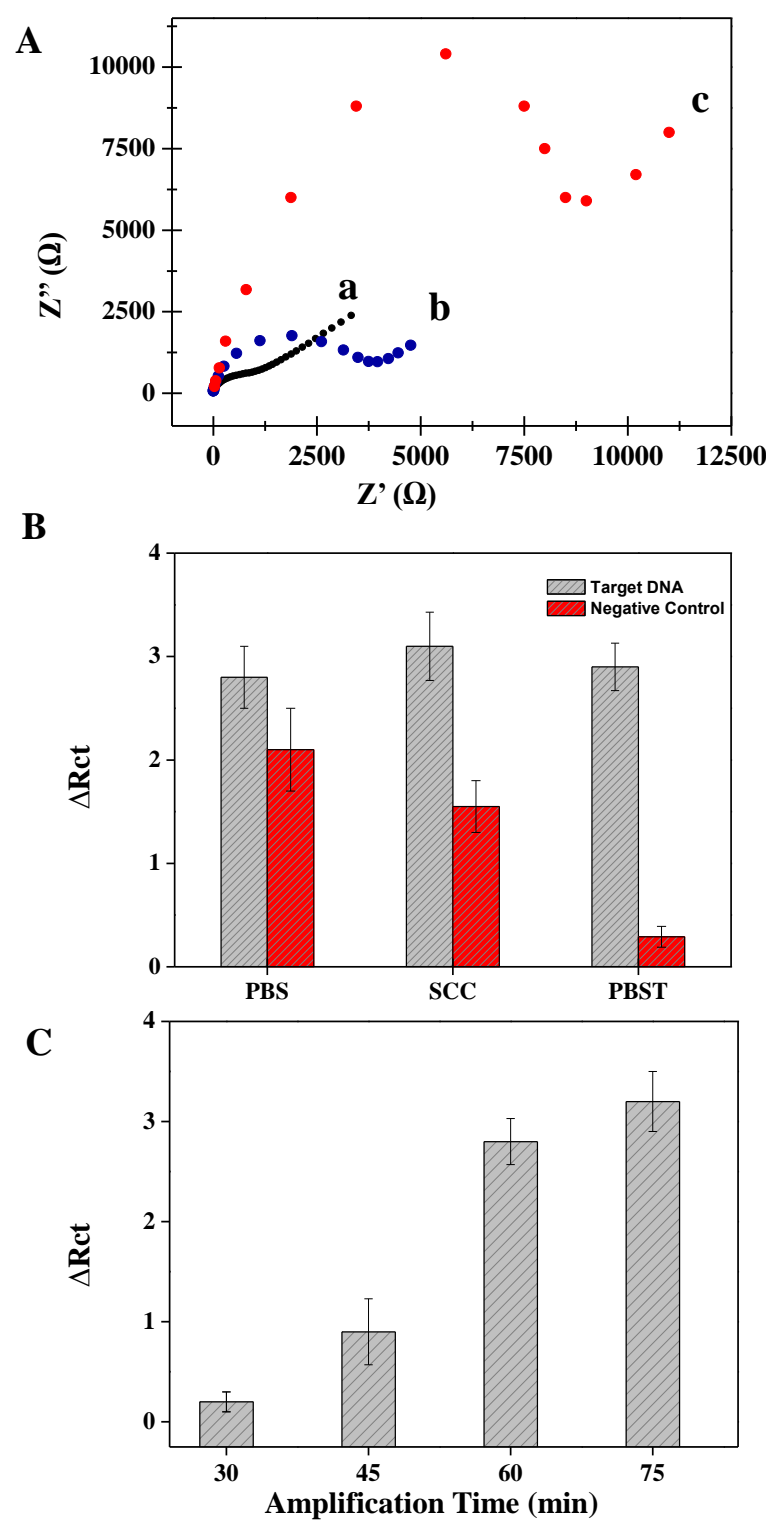

Figure 3: A. Nyquist plots recorded for SPCE-AuNP electrode a) upon SH-(AT $)-F 1$ primer immobilization b) and in situ isothermal RPA with CTV-p20 target concentration of $1 \mathrm{ng} \mu \mathrm{L}^{-1}$ c). B. Effect of washing with different buffers after the in situ isothermal RPA performed for the CTV-p20 (target DNA) and for blank control (NTC) on the analytical signal. DNA concentration: $1 \mathrm{ng} \mu \mathrm{L}^{-1}$. C. Effect of the in situ isothermal RPA amplification time (30, 45, 60 and $75 \mathrm{~min}$ ) on the analytical signal for a CTV-p20 target concentration of $1 \mathrm{ng} \mu \mathrm{L}^{-1}$.

Finally, the effect of the time of the in situ isothermal RPA reaction on the electrochemical signal was also studied. As shown in Figure 3C, no detectable signals were obtained for reaction times below $30 \mathrm{~min} . \mathrm{R}_{\mathrm{ct}}$ values increased then with the reaction time in the range 30 60 min, when a signal saturation was noticed. It's worthy to note that such optimum 
amplification time in solid-phase is longer than the one typically used for the RPA in homogeneous phase $(60 \mathrm{~min})$, as expected. ${ }^{20}$ Furthermore, the lower temperature used probably also contributes to such longer time required.

\subsection{In situ Citrus tristeza-related nucleic acid DNA amplification/detection}

The ability of our biosensor for the quantification of CTV-related DNA was evaluated. The in situ isothermal RPA amplification/detection biosensor on primer-modified SPCE-AuNP electrode was performed for different CTV-p20 target concentrations under the optimized conditions (Primer concentration: $0.1 \mu \mathrm{M}$, primer immobilization time: $2 \mathrm{~h}$, RPA amplification time: $1 \mathrm{~h}$ at room temperature; washing in PBST buffer). According to the EIS Nyquist plot, as the target concentration increased, the diameter of semicircle enlarged as shown at Figure 4A.

The normalized $R_{c t}$ values vs the CTV-p20 target concentrations were plotted (Figure 4B), finding a logarithmic relationship in the range of 1 to $1000 \mathrm{pg} \mu \mathrm{L}^{-1}$, adjusted to the following equation:

$$
\Delta \operatorname{Rct}(\Omega)=0.241 \ln \left[\operatorname{CTV}\left(\operatorname{pg} \mu \mathrm{L}^{-1}\right)\right]+3.62(\mathrm{r}=0.99) \quad\left(\Delta \mathrm{R}_{\mathrm{ct}}=\left(\mathrm{R}-\mathrm{R}_{0}\right) / \mathrm{R}_{0}\right)
$$

The limit of detection (LOD) was found to reach $1 \mathrm{pg} \mu \mathrm{L}^{-1}$ (calculated as the target concentration producing a signal equivalent to the blank signal plus three folds its standard deviation). 
$\mathbf{A}$

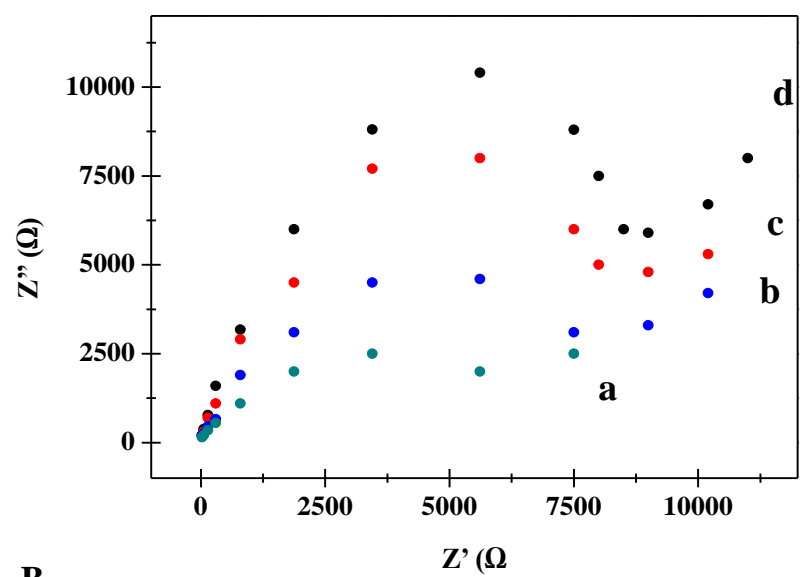

B

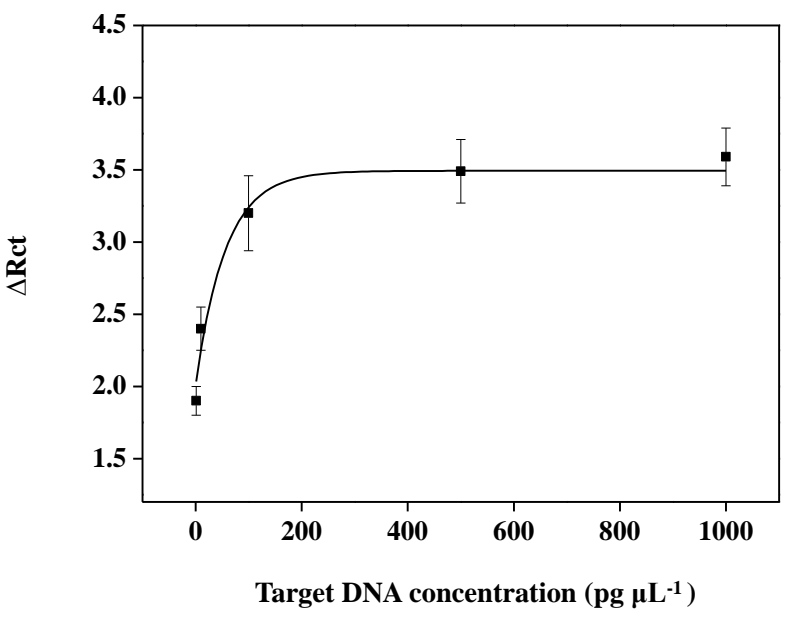

Figure 4. Normalized values corresponding to $\Delta \mathrm{R}_{\mathrm{ct}}=\left(\mathrm{R}-\mathrm{R}_{0}\right) / \mathrm{R}_{0}$ are represented. A. Nyquist plots recorded for SPCE-AuNPs electrodes upon in situ RPA amplification performed for Citrus psorosis virus (CPsV) gene (negative control-NTC) a) and CTV-p20 target at b) 10, c)

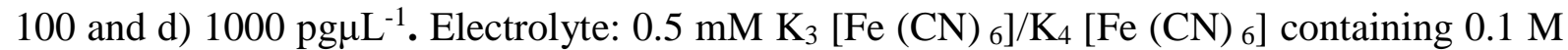
$\mathrm{KCl}$; Potential: $0.2 \mathrm{~V}$; Amplitude: $5 \mathrm{mV}$; Frequency range: $10 \mathrm{KHz}$ to $0.005 \mathrm{~Hz}$. B. Calibration curve obtained by plotting the normalized $R_{c t}$ values $\left(\Delta R_{c t}=\left(R-R_{0}\right) / R_{0}\right)$ vs the logarithm of t CTV-p20 gene target concentration in the range of $1 \mathrm{pg} \mu \mathrm{L}^{-1}$ to $1000 \mathrm{pg} \mu \mathrm{L}^{-1}$. Other experimental conditions as described in the text.

The limit of detection achieved by the label-free in situ isothermal RPA on primer-modified SPCE-AuNP electrodes was 100 times lower than that of the modified RPA assay, showing 
that the integration of in situ isothermal RPA with impedance approach allowed a highly sensitive detection of nucleic acid.

Additionally, specificity studies were performed to examine the ability of our developed in situ RPA sensor to differentiate between CTV-related and non-CTV-related DNAs. These studies were performed with a non-specific gene sequences characteristic of Citrus psorosis virus $(\mathrm{CPsV})$, as it is claimed to be the second important citrus virus, and also Citrus caxicia viroid $(\mathrm{CCaV})$, which is likely to be present in complex infection with $\mathrm{CTV}$ in the infected citrus trees in nature. Under optimized experiment conditions, primer-modified SPCE-AuNP electrodes were coated with RPA solutions prepared with CTV-p20 gene target and controls. Impedance measurements shown in Figure 5A evidence a clear discrimination between the specific and non-specific DNA, demonstrating the specificity of our sensing system to CTVrelated nucleic acid. 
A

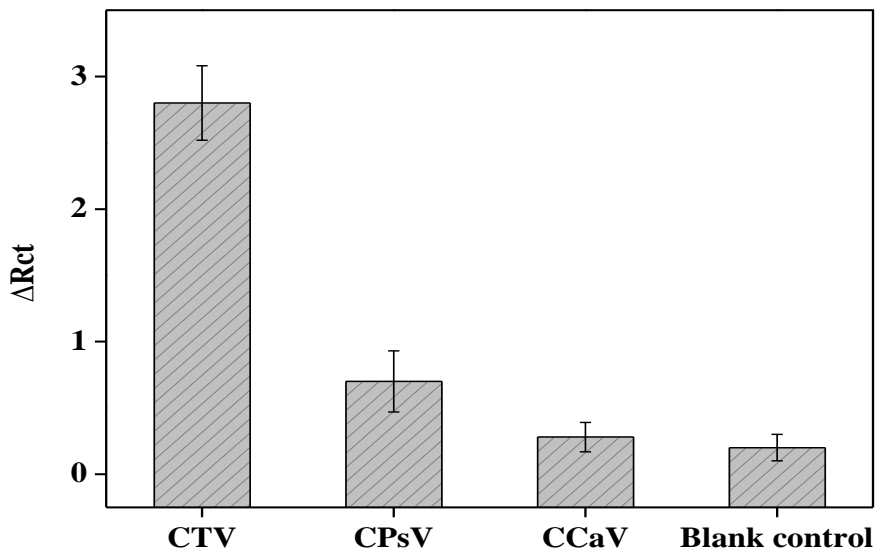

B

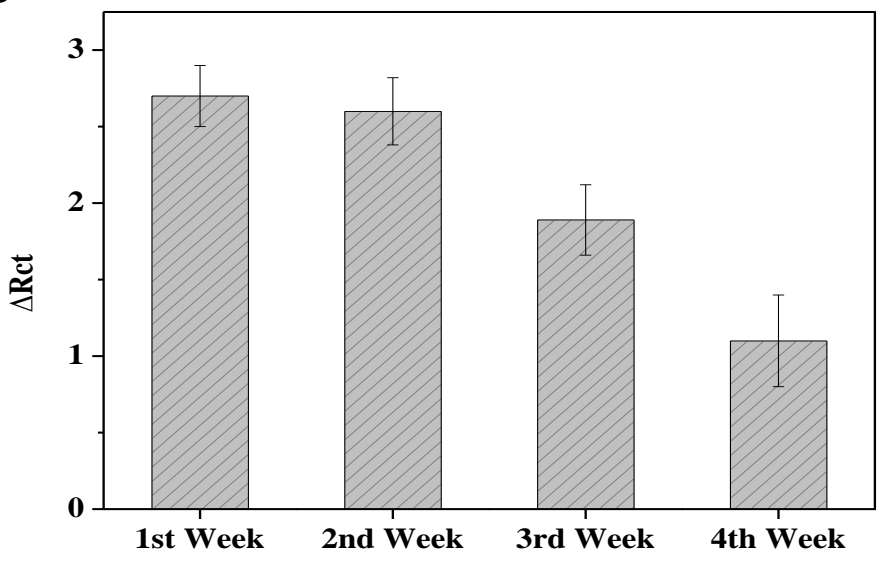

Figure 5. A. Normalized $R_{c t}$ values $\left(\Delta R_{c t}=\left(R-R_{0}\right) / R_{0}\right)$ obtained for in situ RPA performed with specific target CTV-p20 gene and non-specific CPsV and $\mathrm{CCaV}$ sequences, as well as for a blank control B. Effect of storage on the performance of SPCE-AuNP electrodes for in situ isothermal RPA within four weeks.

The storage stability of SPCE-AuNP electrodes was also investigated by monitoring the impedance response of in situ RPA each week up to 1 month. The sensor has showed an extended shelf-life of working for more than three weeks. Along with that, the repeatability of responses for a $100 \mathrm{pg} \mu \mathrm{L}^{-1}$ of CTV-p20 gene target on the thiolated primer-modified SPCEAuNP surfaces was studied through intra- and inter-day assays, obtaining a relative standard deviation (RSD) of $8 \%$ which demonstrated the good performance of this proof-of-concept approach. 


\section{CONCLUSION}

We have developed the first integrated label-free in situ isothermal RPA amplification/detection based on AuNP-modified SPCE employing impedance for the detection of CTV-related nucleic acid. Specific primers for p20 gene of CTV genome were designed and RPA amplified products were investigated by gel electrophoresis. Then, the effect of both reaction volume and amplification temperature was also evaluated by gel analysis. For in situ isothermal RPA, AuNP-modified electrodes were coated with thiolated forward primer ( $\left.\mathrm{SH}-\left(\mathrm{AT}_{7}\right)-\mathrm{F} 1\right)$ to form the sensing layer that recognizes $\mathrm{CTV}-\mathrm{p} 20$ target and start the direct synthesis of duplex DNA onto electrode surface. A simple electrochemical detection of CTV was performed using faradic impedance to characterize the electrochemical performance before and after in situ amplification. Charge transfer resistance parameter was selected to monitor the changes on the electrode surface which results from the immobilization of sensing layer and the amplified duplex DNA. Our in situ isothermal RPA amplification/detection sensor showed a logarithm relation in the range of 1 to $1000 \mathrm{pg} \mu \mathrm{L}^{-1}$ of CTV-related nucleic acid with LOD of $1000 \mathrm{fg} \mu \mathrm{L}^{-1}$ with a total assay time of $80 \mathrm{~min}$ (60 min RPA amplification and 20 min readout). The sensor performance including specificity and storage life along with intra- and inter-day assays was also studied. Moreover, the results demonstrated the good reproducibility of the biosensors with RSD below 10\%. The in situ RPA sensor exhibits great advantages over the modified RPA analyzed by gel electrophoresis in terms of simplicity (no heat source and no label required), sensitivity and portability together with allowing quantitative analysis of nucleic acid. The proposed biosensor is of high potential interest for in-field applications for plant pathogen early detection, which would overcome the limitations of classical molecular methods such as PCR. 


\section{ACKNOWLEDGMENTS}

The ICN2 is funded by the CERCA programme / Generalitat de Catalunya. ICN2 acknowledges the support of the Spanish MINECO through the Severo Ochoa Centers of Excellence Program under Grant SEV2201320295. Mohga Khater thanks Autonomous University of Barcelona for the opportunity of performing this work inside the framework of Biotechnology PhD Programme. 


\section{REFERENCES}

(1) James, A.; Macdonald, J. Expert Rev. Mol. Diagn. 2015, 15, 1475-1489.

(2) Daher, R.K.; Stewart, G.; Boissinot, M.; Bergeron, M.G. Clin. Chem. 2016, 62, 947-958.

(3) Moore, M.D.; Jaykus, L.A. Future Virol. 2017, 12, 421-429.

(4) Lobato, I.M.; Sullivan, C.K. TrAC, Trends Anal. Chem. 2018, 98, 19-35.

(5) Chen, G.; Dong, J., Yuan, Y.; Li, N.; Huang, X.; Cui, X.;Tang, Z. Sci. Rep. 2016, 6, 34582.

(6) Wang, J.; Liu, L.; Wang, J.; Sun, X.; Yuan, W. PloS one, 2017, 12, .e0166903.

(7) Compton, J. Nature 1991, 350, 91-92.

(8) Notomi, T.; Okayama, H.; Masubuchi, H.; Yonekawa, T.; Watanabe, K.; Amino, N.; Hase, T. Nucleic Acids Res. 2000, 28, e63.

(9) Gusev, Y.; Sparkowski, J.; Raghunathan, A.; Ferguson Jr, H.; Montano, J.; Bogdan, N.; Schweitzer, B.; Wiltshire, S.; Kingsmore, S.F.; Maltzman, W.; Wheeler, V. Am. J. Pathol. 2001,159, 63-69.

(10) Vincent, M.; Xu, Y.; Kong, H. EMBO Rep. 2004, 5, 795-800.

(11) Piepenburg, O.; Williams, C.H.; Stemple, D.L.; Armes, N.A. PLoS Biol. 2006, 4, 1115 1121.

(12) Rivas, L.; de la Escosura-Muñiz, A.; Serrano, L.; Altet, L.; Francino, O.; Sánchez, A.; Merkoçi, A. Nano Res. 2015, 8, 3704-3714. 
(13) Sun, K.; Xing, W.; Yu, X.; Fu, W.; Wang, Y.; Zou, M.; Luo, Z.; Xu, D. Parasites vectors 2016, 9, 476.

(14) Wu, YA.D.; Xu, M.J.; Wang, Q.Q.; Zhou, C.X.; Wang, M.; Zhu, X.Q.; Zhou, D.H. Vet. Parasitol. 2017, 243, 199-203.

(15) De la Escosura-Muñiz, A.; Baptista Pires, L.; Serrano, L.; Altet, L.; Francino, O.; Sánchez, A.; Merkoçi, A. Small 2016, 12, 205-213.

(16) Tsaloglou, M. N.; Nemiroski, A.; Camci-Unal, G.; Christodouleas, D. C.; Murray, L. P.; Connelly, J. T.; Whitesides, G. M. Anal. Biochem. 2018, 543, 116-121.

(17) Li, Z.; Liu, Y.; Wei, Q.; Liu, Y.; Liu, W.; Zhang, X.; Yu, Y. PLoS One 2016, 11, e0153359.

(18) Shin, Y.; Perera, A. P.; Kee, J. S.; Song, J.; Fang, Q.; Lo, G. Q.; Park, M. K. Sens. Actuators, B. 2013a , 177, 404-411.

(19) Shin, Y.; Perera, A. P.; Kim, K. W.; Park, M. K. Lab Chip 2013b, 13, 2106-2114.

(20) Del Río, J. S.; Lobato, I. M.; Mayboroda, O.; Katakis, I.; O’Sullivan, C. K. Anal. Bioanal. Chem. 2017, 409, 3261-3269.

(21) Agrios, G. N. Plant pathol. 5th edn, Elsevier Academic Press, 2005.

(22) Punja, Z.K.; De Boer, S.H. Sanfaçon, H. Eds. Biotech and plant disease management; Cabi, 2007.

(23) Alvarez, A. M. Annu. Rev. Phytopathol. 2004, 42, 339-366.

(24) Narayanasamy, P. Detection of fungal pathogens in plants. In Microbial Plant PathogensDetection and Disease Diagnosis: Springer, Dordrecht 2011, 5-199. 
(25) Macario, A.J.; De Macario, E.C. In; Monoclonal Antibodies Against Bacteria; New York State Department of Health, Albany, New York 1985, 213-247.

(26) Comstock, J.C.; Irey, M.S. Plant Dis. 1992, 76, 1033.

(27) Thornton, C.R. Production of monoclonal antibodies to plant pathogens. In Plant Pathology ; Humana Press, Totowa, NJ. 2009, 63-74.

(28) Tomlinson, J.A.; Dickinson, M.J.; Boonham, N. Phytopath. 2010, 100, 143-149.

(29) Ward, E.; Foster, S.J.; Fraaije, B.A.; Mccarteny, H.A. Ann. of Appl. Biol. 2004, 145, 116.

(30) Price, J.A.; Smith, J.; Simmons, A.; Fellers, J.; Rush, C.M. J. of virol. Meth. 2010, 165, 198-201.

(31) Dai, J.; Peng, H.; Chen, W.; Cheng, J.; Wu, Y. J. of App. Micro. 2013, 114, 502-508.

(32) Horsfall J. G.; Cowling E. B., Ed. Plant Disease: An Advanced Treatise; New York, NY: Academic Press, 1977.

(33) Nezhad, A.S. Lab Chip 2014, 14, 2887-2904.

(34) Fang, Y.; Ramasamy, R.P. Biosens. 2015, 5, 537-561.

(35) Martinelli, F.; Scalenghe, R.; Davino, S.; Panno, S.; Scuderi, G.; Ruisi, P.; Villa, P.; Stroppiana, D.; Boschetti, M.; Goulart, L.R.; Davis, C.E. Agron. Sustaine. Dev. 2015, 35, 125 .

(36) Khater, M.; de la Escosura-Muñiz, A.; Merkoçi, A. Biosens. Bioelectron. 2017, 93, 7286. 